\title{
Cytomegalovirus as a cause of hypertensive anterior uveitis in immunocompetent patients
}

\author{
Jin A Choi ${ }^{1}$, Kyu Seop Kim², Younhea Jung ${ }^{2}$, Hae Young Lopilly Park² and Chan Kee Park ${ }^{2 *}$
}

\begin{abstract}
Background: The aims of this study are to investigate the clinical characteristics of patients with anterior hypertensive uveitis and to compare the characteristics between patients in cytomegalovirus (CMV)-positive and CMV-negative groups in their aqueous humor samples. Immunocompetent patients ( $n=42$ ) with a history of chronic and/or recurrent hypertensive anterior uveitis underwent ophthalmic examination and serological tests. Among the 42 patients with hypertensive anterior uveitis, aqueous humor sampling was performed in 21, and they were analyzed for viral deoxyribonucleic acids using the polymerase chain reaction (PCR).

Results: The average age of the 42 patients with hypertensive anterior uveitis was 57.6 years, and 29 (69.0 \%) of the subjects were males. Of the patients, 22 (52.4\%) underwent glaucoma surgery, and the average corneal endothelial cell counts were 1908 cells $/ \mathrm{mm}^{2}$. Among the 21 patients who underwent an aqueous sampling, 6 were positive for CMV-DNA, while 15 were negative. The frequency of glaucoma surgery was similar between groups (CMV positive vs. CMV negative, 66.0 vs. $66.0 \%, P=0.701$ ). However, $66.7 \%$ of the CMV-positive group underwent glaucoma tube shunt surgery, whereas $80 \%$ of the CMV-negative group underwent trabeculectomy or received an ExPRESS glaucoma filtration device (Alcon, Fort Worth, TX) for glaucoma surgery $(P=0.095)$. The corneal endothelial cell counts were significantly lower in the CMV-positive group (CMV positive vs. CMV negative, $1245 \pm 560$ vs. $1981 \pm 387$ cells/mm² $P=0.009$ ).

Conclusions: CMV was found to be an etiological factor in patients with hypertensive anterior uveitis in Korea. Special caution is needed for patients with CMV-induced hypertensive anterior uveitis, considering its adverse effect on the corneal endothelium.
\end{abstract}

Keywords: Glaucoma, Uveitis, Cytomegalovirus, Endothelium, Cornea

\section{Background}

Herpes viruses are known to play a role in the idiopathic anterior uveitis associated with ocular hypertension [1-4]. There are three herpes viruses responsible for ocular inflammation; human cytomegalovirus (CMV), herpes simplex virus (HSV)-1, and varicella zoster virus (VZV). CMV has been recognized as a cause of morbidity and mortality, mostly in immunocompromised individuals $[3,4]$. Recent reports have shown that CMV infection is

\footnotetext{
* Correspondence: ckpark@catholic.ac.kr

2Department of Ophthalmology and Visual Science, Seoul St. Mary's Hospital, College of Medicine, The Catholic University of Korea, Banpo-daero 222,

Seocho-gu, Seoul 137-701, Republic of Korea

Full list of author information is available at the end of the article
}

an emerging cause of anterior uveitis associated with ocular hypertension in immunocompetent subjects $[1,2,5,6]$. $\mathrm{CMV}$ is also an important cause of corneal endotheliitis, particularly in Asian populations [7-12]. However, the pathogenesis of CMV-induced anterior uveitis in immunocompetent patients and the systemic and ocular characteristics of the disease are not well understood.

In the present study, we investigated the clinical characteristics of patients with anterior hypertensive uveitis and compared the ocular and systemic characteristics between CMV-positive and CMV-negative patients in their aqueous humor. Finally, we investigated the factors 
associated with the corneal endothelial cell loss in the hypertensive anterior uveitis patients.

\section{Methods}

This was a retrospective review of patients with anterior hypertensive uveitis who were investigated at Seoul St. Mary's Hospital from March 2009 to June 2014. This study was performed according to the tenets of the Declaration of Helsinki, and the study protocol was approved by the institutional review/ethics boards of the Seoul St. Mary's Hospital, the Catholic University of Korea (IRB number: KC14RISI0513). All of the patients included in this study met the following criteria: (1) anterior uveitis with keratic precipitates (KPs) and (2) increased intraocular pressure (IOP). Patients with the following were excluded: (1) presence of inflammation in vitreous or retina and (2) presence of corneal endothelial changes for a known cause other than anterior uveitis.

All of the participants underwent a comprehensive ophthalmic examination, including a detailed review of medical and ocular histories, best-corrected visual acuity measurement, slit-lamp biomicroscopy, Goldmann applanation tonometry, specular microscopy using a non-contact specular microscope (Konan Noncon Robo, Konan Medical, Inc., Hyogo, Japan), dilated stereoscopic examination of the optic nerve head and fundus, stereoscopic optic disc photography and red-free retinal nerve fiber layer (RNFL) photography (Nonmyd 7; Kowa Company Ltd., Nagoya, Japan), achromatic automated perimetry using the 24-2 Swedish Interactive Threshold Algorithm Standard program (Humphrey Visual Field (VF) Analyzer; Carl Zeiss Meditec, Inc., Dublin, CA, USA), and optical coherence tomography scans (Cirrus OCT, Carl Zeiss Meditec) to measure peripapillary RNFL thickness. Peripapillary RNFL thickness was determined three times at 256 points around a set diameter $(3.4 \mathrm{~mm})$ circle using the fast RNFL program. Only wellfocused, well-centered images without eye movement and a signal strength $\geq 7$ were used. A global average RNFL thickness provided by the software was used for the analysis. All of the patients underwent a laboratory work-up (including complete blood count, erythrocyte sedimentation rate analysis, white cell count and differential, blood chemistry) and serologic screening for IgM and IgG anti-CMV, HSV, and VZV.

Among the 42 patients with hypertensive anterior uveitis, aqueous sampling was performed in 21. Using a 30 -gauge needle, $100 \mu \mathrm{L}$ aqueous humor was aspirated under aseptic conditions and subjected to a polymerase chain reaction (PCR) assay for CMV, HSV1, and HSV2 DNA. DNA was extracted from the aqueous humor samples using a QIAamp DNA minikit (Qiagen, Valencia, CA, USA). Quantitative CMV-DNA PCR testing was performed using an AccuPower CMV Quantitative PCR Kit
(Bioneer, Daejun, Republic of Korea). For HSV PCR, the HSV 1/2 PCR Kit (Bio-Core, Seoul, Republic of Korea) was used.

Glaucoma was defined as having glaucomatous disc appearance (thinning of neuroretinal rim, peripapillary hemorrhage, or localized pallor) associated with a typical reproducible VF defect evident on standard automated perimetry. A glaucomatous VF defect was defined as a glaucoma hemifield test result outside normal limits and the presence of at least three contiguous points in the pattern deviation plot with $P$ values $<5 \%$, with at least one point associated with a $P$ value $<1 \%$ on two consecutive reliable VF examinations.

Patients were classified according to the duration of active intraocular inflammation. Patients with at least 3 months of active intraocular inflammation were considered to have chronic uveitis, and other patients to have recurrent episode of acute uveitis, which was normalized between attacks [2]. Glaucoma treatment was started in a step-wise manner; anti-glaucoma medication (beta-blocker, alpha-2 agonists, topical acetazolamide, and prostaglandin), and finally, glaucoma surgery. Glaucoma surgery was chosen among conventional trabeculectomy/ExPRESS glaucoma filtration device (Alcon Laboratories, Fort Worth, TX, USA) or Ahmed glaucoma valve implant (New World Medical, Inc., Rancho Cucamonga, CA, USA) surgery, considering preoperative IOP and severity of glaucomatous optic disc damage.

\section{Statistical analysis}

For independent samples, the non-parametric MannWhitney $U$ test and the $\chi^{2}$ test were used to compare between-group means and percentages. Multivariable analysis was performed using simple and multiple linear regressions for corneal endothelial cell counts according to the presence of CMV-DNA in the aqueous humor. First, we adjusted for age and gender (model 1). Then we adjusted for age, gender, lens status, and history of glaucoma surgery (model 2). A $P$ value $<0.05$ was considered to statistically significant. All of the statistical analyses were performed using the SPSS software (ver. 14.0 for Windows; SPSS Inc.).

\section{Results}

The clinical features of our patients are summarized in Table 1 . The average age of the 42 patients with hypertensive anterior uveitis was 57.6 years, and $29(69.0 \%)$ of the subjects were males. In total, 22 (52.4\%) patients underwent glaucoma surgery, and the mean corneal endothelial cell counts were 1908 cells $/ \mathrm{mm}^{2}$.

Among the 21 patients who underwent aqueous sampling, six were positive for CMV-DNA, whereas 15 were negative (Table 2). The CMV-positive group was significantly younger and more myopic than the CMV- 
Table 1 Clinical parameters of 42 patients with hypertensive anterior uveitis

\begin{tabular}{ll}
\hline Gender (M/F) & $29: 13$ \\
Age (range), years & $57.6(25-88)$ \\
Spherical equivalent, D & $-2.6(-11.25-0.00)$ \\
Glaucoma operation,\% & $22(52.4 \%)$ \\
Corneal endothelial cell count, cells/mm² & $1908(625-3067)$ \\
Unilaterality & $39(92.9 \%)$ \\
KPs at baseline examination & $28(67.8 \%)$ \\
Anterior chamber reaction with 1+ or less & $37(88.1 \%)$ \\
Severe peripheral anterior synechiae & $0(0.0 \%)$ \\
Typical feature of P-S syndrome & $14(33.3 \%)$ \\
\hline
\end{tabular}

negative group (CMV positive vs. CMV negative: $47.5 \pm$ 14.8 vs. $67.6 \pm 11.8$ years, $P=0.006 ;-3.6 \pm 4.2$ vs. $0.0 \pm$ $1.6 \mathrm{D}, P=0.031)$. The frequency of glaucoma surgery was similar between the groups (CMV positive vs. CMV negative, 66.0 vs. $66.0 \%, P=0.701)$. However, $66.7 \%$ of CMV-positive group had an Ahmed glaucoma valve implanted, whereas $80 \%$ of the CMV-negative group underwent trabeculectomy or use of the ExPRESS glaucoma filtration device $(P=0.095)$. The corneal endothelial cell counts were significantly lower in the CMV-positive group (CMV positive vs. CMV negative: $1245 \pm 560$ vs. $1981 \pm$ 387 cells $\left./ \mathrm{mm}^{2} ; P=0.009\right)$.

Table 3 shows the laboratory characteristics of subjects with and without $\mathrm{CMV}-\mathrm{PCR}(+)$ in the aqueous humor. In the CMV-positive subjects, the percentage of monocytes tended to be lower than in the CMV-negative

Table 2 Comparisons of clinical and immunologic characteristics in subjects with or without CMV in aqueous humor

\begin{tabular}{|c|c|c|c|}
\hline Characteristics & CMV-positive subjects $n=6$ & CMV-negative subjects $n=15$ & $P$ value \\
\hline \multicolumn{4}{|l|}{ Demographic characteristics } \\
\hline Male, $n(\%)$ & $6(100 \%)$ & $13(86.7 \%)$ & 0.500 \\
\hline Age, years & $47.5 \pm 14.8$ & $67.6 \pm 11.8$ & 0.006 \\
\hline \multicolumn{4}{|l|}{ Ocular characteristics } \\
\hline Initial BCVA & $0.65 \pm 0.29$ & $0.58 \pm 0.29$ & 0.569 \\
\hline Final BCVA & $0.47 \pm 0.46$ & $0.52 \pm 0.30$ & 0.733 \\
\hline Spherical equivalent, D & $-3.6 \pm 4.2$ & $0.0 \pm 1.6$ & 0.031 \\
\hline Axial length, mm & $25.7 \pm 1.5$ & $24.4 \pm 0.7$ & 0.053 \\
\hline Glaucoma, $n$ (\%) & $6(100 \%)$ & $13(86.7 \%)$ & 0.347 \\
\hline Average RNFL thickness, $\mu \mathrm{m}$ & $66.2 \pm 16.7$ & $77.8 \pm 19.1$ & 0.132 \\
\hline Corneal endothelial cell count, mm² & $1245 \pm 560$ & $1981 \pm 387$ & 0.009 \\
\hline Unilaterality, n (\%) & 83.3 & 80.0 & 0.684 \\
\hline KPs at baseline examination, $n(\%)$ & 83.3 & 73.3 & 0.550 \\
\hline Presence of PAS, $n(\%)$ & $4(66.7 \%)$ & $5(33.3 \%)$ & 0.331 \\
\hline Anterior chamber reaction with $1+$ or less, $n(\%)$ & 100.0 & 92.9 & 0.714 \\
\hline Lens status, phakic, $n(\%)$ & $5(83.3 \%)$ & $5(33.3 \%)$ & 0.055 \\
\hline Baseline IOP, mmHg & $28.83 \pm 8.25$ & $22.73 \pm 7.86$ & 0.132 \\
\hline Maximum IOP, mmHg & $37.17 \pm 8.03$ & $39.53 \pm 13.02$ & 0.622 \\
\hline Final IOP, mmHg & $13.3 \pm 3.44$ & $13.5 \pm 5.05$ & 0.950 \\
\hline Number of anti-glaucoma medication, $n$ & $2.67 \pm 0.81$ & $2.67 \pm 0.81$ & 0.970 \\
\hline Course of uveitis & & & 0.544 \\
\hline Chronic, $n(\%)$ & $4(66.7 \%)$ & $13(86.7 \%)$ & \\
\hline Recurrent, $n(\%)$ & $2(33.3 \%)$ & $2(13.3 \%)$ & \\
\hline Glaucoma operation, $n(\%)$ & $4(66.7 \%)$ & $10(66.7 \%)$ & 0.701 \\
\hline Choice of glaucoma operation & & & 0.095 \\
\hline Ahmed valve, $n(\%)$ & $3(75.0 \%)$ & $2(20.0 \%)$ & \\
\hline Trabeculectomy or ExPRESS , $n(\%)$ & $1(25.0 \%)$ & $8(80.0 \%)$ & \\
\hline HSV PCR positivity, n (\%) & $0(0.0 \%)$ & $1(6.2 \%)$ & 0.727 \\
\hline CMV RQ PCR, copies/mL & $46,048.8 \pm 91,334.5$ & Negative & $\mathrm{n} / \mathrm{a}$ \\
\hline
\end{tabular}


Table 3 Comparison of laboratory findings in subjects with or without CMV-PCR $(+)$ in aqueous humor

\begin{tabular}{|c|c|c|c|}
\hline Characteristics & CMV-positive subjects $n=6$ & CMV-negative subjects $n=15$ & $P$ value \\
\hline \multicolumn{4}{|l|}{ Complete blood count } \\
\hline WBC count, cells/ML & $7300 \pm 900$ & $6,700 \pm 1900$ & 0.590 \\
\hline Seg, \% & $54.4 \pm 8.7$ & $55.9 \pm 7.7$ & 0.677 \\
\hline Lymp, \% & $35.0 \pm 6.6$ & $31.9 \pm 7.1$ & 0.424 \\
\hline Mono, \% & $6.5 \pm 0.7$ & $7.8 \pm 1.6$ & 0.055 \\
\hline Eosinophil, \% & $3.5 \pm 1.8$ & $3.8 \pm 3.2$ & 0.970 \\
\hline Basophil, \% & $0.6 \pm 0.3$ & $0.5 \pm 0.2$ & 0.302 \\
\hline RBC count, $10^{6} / \mu \mathrm{L}$ & $5.0 \pm 0.5$ & $4.4 \pm 0.6$ & 0.059 \\
\hline Hemoglobin g/dl & $15.5 \pm 1.4$ & $13.9 \pm 2.0$ & 0.070 \\
\hline Platelet count, $10^{3} / \mu \mathrm{L}$ & $247.5 \pm 51.0$ & $220.8 \pm 58.8$ & 0.329 \\
\hline $\mathrm{ESR}, \mathrm{mm} / \mathrm{h}$ & $10.5 \pm 7.6$ & $31.8 \pm 32.7$ & 0.283 \\
\hline \multicolumn{4}{|l|}{ Blood chemistry } \\
\hline $\mathrm{FBS}, \mathrm{mg} / \mathrm{dL}$ & $103.7 \pm 18.7$ & $100.5 \pm 44.1$ & 0.519 \\
\hline AST, IU/L & $23.3 \pm 3.3$ & $23.6 \pm 10.5$ & 0.367 \\
\hline ALT, IU/L & $28.7 \pm 10.5$ & $27.2 \pm 15.7$ & 0.590 \\
\hline BUN, mg/dL & $15.3 \pm 4.7$ & $17.8 \pm 6.7$ & 0.261 \\
\hline Creatinine, mg/dL & $0.9 \pm 0.1$ & $1.0 \pm 0.3$ & 0.971 \\
\hline $\mathrm{GFR}, \mathrm{ml} / \mathrm{min} / 1.73 \mathrm{~m}^{2}$ & $91.1 \pm 8.9$ & $79.2 \pm 19.1$ & 0.178 \\
\hline $\mathrm{Na}, \mathrm{mEq} / \mathrm{L}$ & $142.3 \pm 1.2$ & $141.9 \pm 3.2$ & 0.858 \\
\hline $\mathrm{K}, \mathrm{mEq} / \mathrm{L}$ & $4.4 \pm 0.4$ & $4.3 \pm 0.5$ & 0.914 \\
\hline \multicolumn{4}{|l|}{ Immunology } \\
\hline HSV IgM positivity, n (\%) & $1(16.7 \%)$ & $0(0.0 \%)$ & 0.273 \\
\hline HSV IgG, titer, AU/mL & $3.3 \pm 1.4$ & $6.5 \pm 6.8$ & 0.320 \\
\hline VZV IgM positivity, n (\%) & $1(16.7 \%)$ & $0(0.0 \%)$ & 0.273 \\
\hline VZV IgG titer, AU/mL & $5.3 \pm 3.1$ & $5.0 \pm 2.2$ & 1.000 \\
\hline CMV IgM positivity, $n$ (\%) & $0(0.0 \%)$ & $0(0.0 \%)$ & $\mathrm{n} / \mathrm{a}$ \\
\hline CMV IgG titer, AU/mL & $54.7 \pm 15.3$ & $55.7 \pm 16.4$ & 1.000 \\
\hline
\end{tabular}

HSV herpes simplex virus, VZV varicella zoster virus, CMV cytomegalovirus, ESR erythrocyte sedimentation rate, FBS fasting blood sugar, $A S T$ aspartate aminotransferase, $A L T$ alanine aminotransferase, $B U N$ blood urea nitrogen, GFR glomerular filtration rate, $n / a$ not applicable

subjects, with marginal significance $(P=0.055)$, whereas other parameters did not differ between the groups. The presence of CMV in the aqueous humor was significantly associated with corneal endothelial cell count after controlling for age and gender $(P=0.023)$, which was maintained after additional adjustment for lens status and history of glaucoma surgery $(P<0.001$; Table 4$)$. The clinical information of the $6 \mathrm{CMV}+$ patients was described in the Additional file 1, and two representative cases with antiviral treatment are discussed.

\section{Case reports}

\section{Patient 1}

A 68-year-old man had hypertensive anterior uveitis of his left eye with a recurrence rate of one to two times a month since 2010. On slit-lamp examination at Seoul St. Mary's Hospital in October 2012, fine KPs in the lower part of the cornea and mild inflammatory reaction in the
Table 4 Association between the presence CMV DNA in aqueous and corneal endothelial cell count in patients with anterior hypertensive uveitis

\begin{tabular}{llll}
\hline & $\begin{array}{l}\text { Model 1 } \\
\text { Unadjusted }\end{array}$ & $\begin{array}{l}\text { Model 2 } \\
\text { Adjusted for } \\
\text { age and gender }\end{array}$ & $\begin{array}{l}\text { Model 3 } \\
\text { Adjusted for age, } \\
\text { gender, lens status, } \\
\text { and history of } \\
\text { glaucoma surgery } \\
B(\mathrm{Cl})\end{array}$ \\
\hline CMV positivity & 672.4 & $B(\mathrm{Cl})$ & 1034.2 \\
& $(77.0-1267.9)$ & $(116.4-1352.4)$ & $(631.3-1437.1)$ \\
$P$ value & 0.029 & 0.023 & $<0.001$
\end{tabular}

$B$ beta coefficient, $\mathrm{Cl}$ confidence interval 
anterior chamber were seen. The corneal endothelial cell count of the left eye was 2141 cells $/ \mathrm{mm}^{2}$, and the IOP was $22 \mathrm{mmHg}$ with two topical antiglaucoma medications. He showed glaucomatous optic disc changes, with a mean deviation of $-9.50 \mathrm{~dB}$. Despite the use of topical steroids and three antiglaucoma medications for 5 months, his IOP was not controlled, and his corneal endothelial cell count in the left eye decreased to 1245 cells $/ \mathrm{mm}^{2}$. A CMV-quantitative PCR analysis of aqueous humor samples for the left eye revealed 229,000 copies/mL CMVDNA, but no HSV-DNA. Thus, an oral course of valacyclovir $(90 \mathrm{mg} /$ day) was started. The ExPRESS glaucoma filtration device (P-200) was implanted under a scleral flap. Oral valacyclovir $(900 \mathrm{mg} /$ day $)$ was continued for 10 days, and anterior chamber tapping revealed 66,600 copies $/ \mathrm{mL}$ CMV-DNA. Oral valacyclovir treatment ( $450 \mathrm{mg} /$ day) was continued for another 14 days, and repeated anterior chamber tapping revealed 630 copies $/ \mathrm{mL}$ CMV-DNA. After glaucoma surgery, the anterior chamber had a rare to +1 grade inflammation, and IOP was well controlled in a range of $6-9 \mathrm{mmHg}$. However, 5 months later, his corneal endothelial cell count was found to have decreased further, to 981 cells $/ \mathrm{mm}^{2}$ (Fig. 1).

\section{Patient 2}

A 64-year-old man had hypertensive anterior uveitis of his left eye with a recurrence rate of one to two times a month since 1991. He had been diagnosed with PosnerSchlossman syndrome, but chronic inflammation in the anterior chamber with uncontrolled IOP elevation was seen, and he was referred to Seoul St. Mary's Hospital for glaucoma surgery. At the initial visit, mutton-fat keratic precipitates were noted in the central cornea with minimal anterior chamber reaction (Fig. 2). IOP was $21 \mathrm{mmHg}$ with three antiglaucoma medications, and high pigmentation was noted in the anterior chamber angle. Severe glaucomatous optic disc was seen, with a mean deviation of $-18.20 \mathrm{~dB}$. The corneal endothelial cell count of the left eye was 1310 cells $/ \mathrm{mm}^{2}$. A CMVquantitative PCR analysis of an aqueous humor sample for the left eye revealed 44,609 copies/mL CMV-DNA, but no HSV-DNA. Oral valacyclovir treatment (900 mg/day) was started, and an Ahmed glaucoma valve was implanted. After 14 days of oral valacyclovir treatment, the aqueous humor showed 6980 copies/mL CMV-DNA. Oral valacyclovir was continued for 14 days, and further anterior chamber tapping showed 450 copies/mL CMV-DNA. After 1 month, the corneal endothelial cell count of the left eye was 1310 cells $/ \mathrm{mm}^{2}$.

\section{Discussions}

We reported the clinical characteristics of hypertensive anterior uveitis (Table 1), which occurred unilaterally (93\%), predominantly in middle-aged (57.6 \pm 17.0 years) males (69.0\%; Table 1$)$. Despite seemingly mild intraocular inflammation of the anterior chamber in the majority of patients $(88.1 \%)$ and the absence of peripheral anterior synechiae $(0 \%)$, glaucoma surgeries were required in over half of the patients $(52.4 \%)$. The male dominance in hypertensive anterior uveitis is consistent with previous results in non-Korean populations [4, 7]. Among the patients who underwent aqueous sampling, six (28.6 \%) patients were positive for CMV-DNA. This prevalence is similar to the previous studies, reporting $22.8 \%$ of anterior uveitis associated with raised IOP $[1,4]$.

Notably, the corneal endothelial cell count in the CMV-positive subjects was significantly lower than in the CMV-negative subjects $(P=0.009$; Table 2$)$. This association between the presence of CMV-DNA and the corneal endothelial cell count was more evident after adjusting for age, gender, lens status, and history of glaucoma surgery $(P<0.001$; Table 3$)$. Previous studies demonstrated that $\mathrm{CMV}$ is an important pathogen for chronic corneal endotheliitis, particularly in Asian

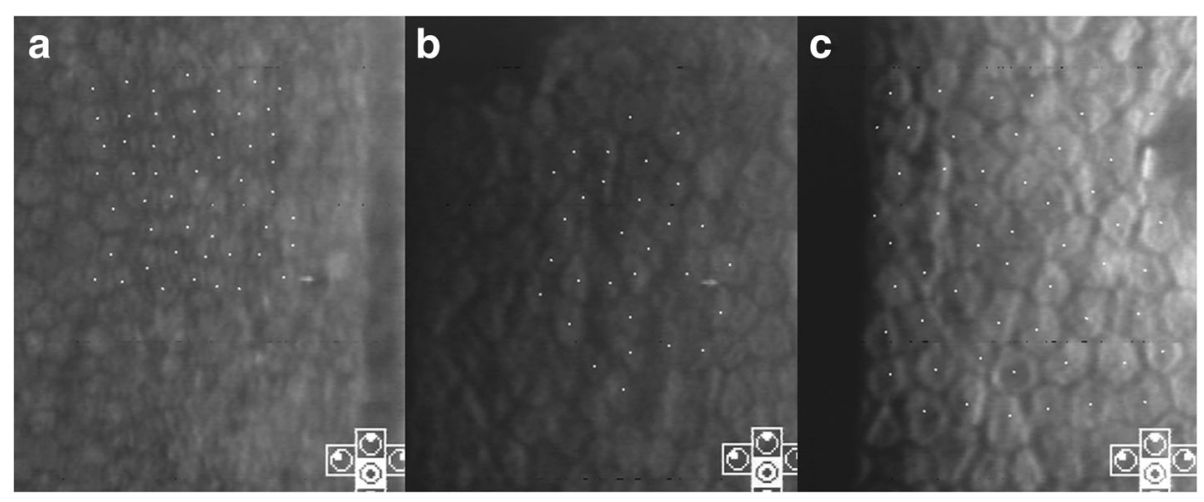

Fig. 1 Case 1: serial follow-up of specular microscopy. At the initial visit, the corneal endothelial count in the left eye was 2141 cells/mm² (a). After topical steroid and three antiglaucoma medications for 5 months, the corneal endothelial cell count decreased to $1245 \mathrm{cells} / \mathrm{mm}^{2}$ (b). A CMV-quantitative PCR analysis of aqueous humor samples revealed 229,000 copies/mL CMV-DNA. After valacyclovir treatment for 1 month, repeated anterior chamber tapping revealed 630 copies $/ \mathrm{mL}$ CMV-DNA. However, the corneal endothelial cell count had decreased further, to $981 \mathrm{cells} / \mathrm{mm}^{2}$ (c) 


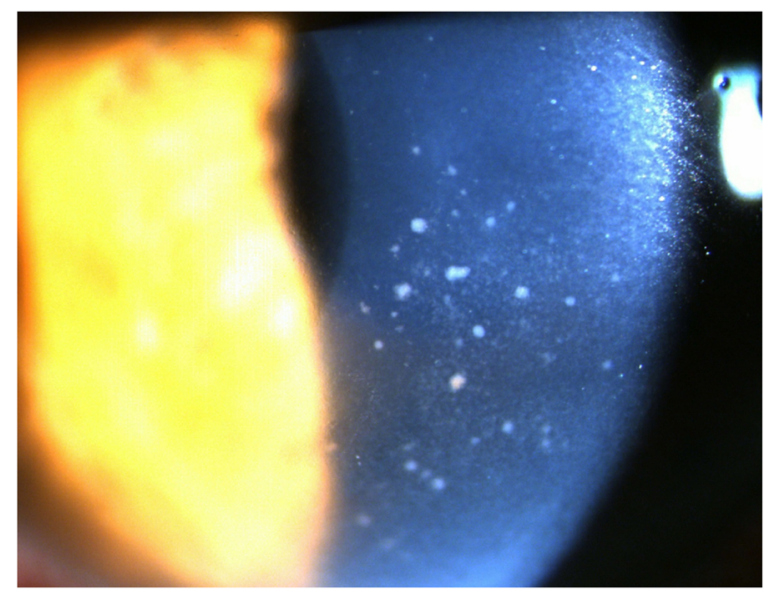

Fig. 2 Case 2: slit lamp photograph showing diffuse mutton-fat keratic precipitates within the central area of the cornea. There was mild inflammation in the anterior chamber

populations $[7-9,13]$. This study confirmed that CMV is a major cause of corneal endothelial cell loss in patients with hypertensive anterior uveitis.

Evidence of valacyclovir's efficacy was seen in our study, using serial follow-up of CMV-DNA copy number and corneal endothelial cell counts in two case patients. After 1 month of therapy, CMV-DNA copy numbers decreased dramatically in both patients. Considering that patient 1 showed very high CMV-DNA copy numbers $(44,609$ copies $/ \mathrm{mL})$, it seems that one episode of acutely increased viral load is sufficient to cause extensive corneal endothelial cell loss. Consistent with our study, Kandori et al. [11] also reported a significant correlation between CMV viral load and corneal endothelial cell loss in CMV-associated uveitis.

We found that the proportion of monocytes tended to be lower in CMV-positive subjects, with marginal significance $(P=0.053$; Table 2$)$. Monocytes are the primary cell type of CMV persistence within the peripheral blood mononuclear cells [14]. CMV infection of monocytes induces trans-endothelial migration and monocyte to macrophage differentiation, which is productive for CMV replication [15]. Although the reason is unclear, CMV-induced differentiation of monocytes into macrophages may be associated with the lower proportion of monocytes in CMV-positive subjects in this study.

We found that the CMV-positive subjects were significantly younger $(P=0.006$, Table 2$)$. Generally, CMV seropositivity increases with age and serves as an immune risk phenotype, which is associated with survival in an older population $[16,17]$. The current understanding of the mechanisms by which CMV reactivates in relatively young immunocompetent subjects is very limited. CMV is unlikely to cause clinically significant symptoms as long as it is maintained in balance by the host immune system [18]. However, recent literature suggests that CMV is associated with the pathogenesis of cardiovascular diseases, such as atherosclerosis, autoimmune disease, and even certain cancers $[19,20]$. It is known that CMV can be reactivated when circulating monocytes with latent CMV are recruited to sites of inflammation [20]. For this reactivation, inflammatory cytokines, such as tumor necrosis factor and interferon, are known to play a role $[21,22]$. In this regard, it is suggested that chronic inflammation in the anterior chamber may trigger CMV reactivation, which in turn, aggravates the inflammatory condition. In addition, CMV anterior uveitis is recalcitrant to topical steroid treatment [3, 4]. Recent reports show evidence that local immunosuppression by topical steroid use increases the risk of CMV infection in immunocompetent patients [23-26]. In addition, there is possibility that the frequent use of prostaglandin eyedrops have play an important role for worsening, including the uncontrolled glaucoma, considering previous reports regarding the complications from glaucoma eyedrops in uveitis [27-29].

\section{Conclusions}

In conclusion, we found that CMV was a significant etiological factor in hypertensive anterior uveitis patients in Korea. In CMV-associated uveitis, extensive corneal endothelial cell damage may occur, even with effective anti-viral medication. CMV-associated hypertensive anterior uveitis patients were younger compared to CMVnegative uveitis patients. Special caution is needed for patients with CMV-positive hypertensive anterior uveitis, given its adverse effects on the corneal endothelium.

\section{Additional file}

Additional file 1: Table S1. Demographic data and clinical manifestations of patients with the presence of cytomegalovirus in the aqueous. (DOCX $15 \mathrm{~kb}$ )

\section{Acknowledgements}

Not applicable.

\section{Funding}

The authors wish to acknowledge of the financial support of the National Research Foundation of Korea Grant funded by the Korean government (MSIP) (No. NRF- 2016R1C1B1011287).

\section{Authors' contributions}

JAC and CKP contributed to the conception and design. JAC, KSK, and YHJ contributed to the acquisition of data and analysis and interpretation of data. JAC contributed in drafting the manuscript. HYLP contributed in revising the manuscript. CKP gave the final approval of the version to be published. All authors read and approved the final manuscript. 


\section{Ethics approval}

The study protocol was approved by the institutional review/ethics boards of Seoul St. Mary's Hospital, the Catholic University of Korea (IRB number: KC14RISI0513).

\section{Author details}

'Department of Ophthalmology and Visual Science, St. Vincent's Hospital, College of Medicine, The Catholic University of Korea, 93-6, Ji-dong, Paldal-gu, Suwon, Kyonggi-do 442-060, Republic of Korea. ${ }^{2}$ Department of Ophthalmology and Visual Science, Seoul St. Mary's Hospital, College of Medicine, The Catholic University of Korea, Banpo-daero 222, Seocho-gu, Seoul 137-701, Republic of Korea.

Received: 11 April 2016 Accepted: 22 August 2016

Published online: 09 September 2016

\section{References}

1. Chee SP, Bacsal K, Jap A, Se-Thoe SY, Cheng CL, Tan BH (2008) Clinica features of cytomegalovirus anterior uveitis in immunocompetent patients. Am J Ophthalmol 145:834-840

2. van Boxtel LA, van der Lelij A, van der Meer J, Los LI (2007) Cytomegalovirus as a cause of anterior uveitis in immunocompetent patients. Ophthalmology 114:1358-1362

3. Jap A, Chee SP (2010) Emerging forms of viral uveitis in the developing world. Int Ophthalmol Clin 50:155-171

4. Jap A, Chee SP (2011) Viral anterior uveitis. Curr Opin Ophthalmol 22:483-488

5. Park SW, Yu HG (2013) Association of cytomegalovirus with idiopathic chronic anterior uveitis with ocular hypertension in Korean patients. Ocul Immunol Inflamm 21:192-196

6. Knox DL (2008) Clinical features of cytomegalovirus anterior uveitis in immunocompetent patients. Am J Ophthalmol 146:625, author reply 625-626

7. Koizumi N, Inatomi T, Suzuki T et al (2015) Clinical features and management of cytomegalovirus corneal endotheliitis: analysis of 106 cases from the Japan corneal endotheliitis study. Br J Ophthalmol 99:54-58

8. Kobayashi A, Yokogawa H, Higashide T, Nitta K, Sugiyama K (2012) Clinical significance of owl eye morphologic features by in vivo laser confocal microscopy in patients with cytomegalovirus corneal endotheliitis. Am J Ophthalmol 153:445-453

9. Chee SP, Bacsal K, Jap A, Se-Thoe SY, Cheng CL, Tan BH (2007) Corneal endotheliitis associated with evidence of cytomegalovirus infection. Ophthalmology 114:798-803

10. Sungur GK, Hazirolan D, Yalvac IS, Ozer PA, Aslan BS, Duman S (2010) Incidence and prognosis of ocular hypertension secondary to viral uveitis. Int Ophthalmol 30:191-194

11. Kandori M, Miyazaki D, Yakura K, Komatsu N, Touge C, Ishikura R, Inoue Y (2013) Relationship between the number of cytomegalovirus in anterior chamber and severity of anterior segment inflammation. Jpn J Ophthalmol 57(6):497-502

12. Lewkowicz D, Willermain F, Relvas $L$ et al (2015) Clinical outcome of hypertensive uveitis. J Ophthalmol 2015:974870

13. Chee SP, Jap A (2011) Immune ring formation associated with cytomegalovirus endotheliitis. Am J Ophthalmol 152:449-453, e441

14. Taylor-Wiedeman J, Sissons JG, Borysiewicz LK, Sinclair JH (1991) Monocytes are a major site of persistence of human cytomegalovirus in peripheral blood mononuclear cells. J Gen Virol 72:2059-2064

15. Smith MS, Bentz GL, Alexander JS, Yurochko AD (2004) Human cytomegalovirus induces monocyte differentiation and migration as a strategy for dissemination and persistence. J Virol 78:4444-4453

16. Wikby A, Johansson B, Olsson J, Löfgren S, Nilsson BO, Ferguson F (2002) Expansions of peripheral blood CD8 T-lymphocyte subpopulations and an association with cytomegalovirus seropositivity in the elderly: the Swedish NONA immune study. Exp Gerontol 37:445-453

17. Solana R, Tarazona R, Aiello AE et al (2012) CMV and immunosenescence: from basics to clinics. Immun Ageing 9:23

18. Reeves MB, MacAry PA, Lehner PJ, Sissons JG, Sinclair JH (2005) Latency, chromatin remodeling, and reactivation of human cytomegalovirus in the dendritic cells of healthy carriers. Proc Natl Acad Sci U S A 102:4140-4145

19. Halenius A, Hengel $\mathrm{H}$ (2014) Human cytomegalovirus and autoimmune disease. Biomed Res Int 2014:472978

20. Söderberg-Nauclér C (2008) HCMV microinfections in inflammatory diseases and cancer. J Clin Virol 41:218-223
21. Prösch S, Heine AK, Volk HD, Krüger DH (2001) CCAAT/enhancer-binding proteins alpha and beta negatively influence the capacity of tumor necrosis factor alpha to up-regulate the human cytomegalovirus IE1/2 enhancer/ promoter by nuclear factor kappaB during monocyte differentiation. J Biol Chem 276:40712-40720

22. Prösch S, Staak K, Stein J et al (1995) Stimulation of the human cytomegalovirus IE enhancer/promoter in HL-60 cells by TNFalpha is mediated via induction of NF-kappaB. Virology 208:197-206

23. Sims JL, Chee SP (2010) Cytomegalovirus endotheliitis following fluocinolone acetonide (Retisert) implant. Eye (Lond) 24:197-198

24. Tugal-Tutkun I, Araz B, Cagatay A (2010) CMV retinitis after intravitreal triamcinolone acetonide injection in a patient with Behçet's uveitis. Int Ophthalmol 30:591-593

25. Ufret-Vincenty RL, Singh RP, Lowder CY, Kaiser PK (2007) Cytomegalovirus retinitis after fluocinolone acetonide (Retisert) implant. Am J Ophthalmol 143:334-335

26. Park UC, Kim SJ, Yu HG (2011) Cytomegalovirus endotheliitis after fluocinolone acetonide (Retisert) implant in a patient with Behçet uveitis. Ocul Immunol Inflamm 19:282-283

27. Goyal R, Ram AR (2000) Brimonidine tartarate $0.2 \%$ (Alphagan) associated granulomatous anterior uveitis. Eye (Lond) 14:908-910

28. Cates CA, Jeffrey MN (2003) Granulomatous anterior uveitis associated with $0.2 \%$ topical brimonidine. Eye (Lond) 17:670-671

29. Warwar RE, Bullock JD, Ballal D (1998) Cystoid macular edema and anterior uveitis associated with latanoprost use. Experience and incidence in a retrospective review of 94 patients. Ophthalmology 105:263-268

\section{Submit your manuscript to a SpringerOpen ${ }^{\circ}$ journal and benefit from:}

- Convenient online submission

- Rigorous peer review

- Immediate publication on acceptance

- Open access: articles freely available online

- High visibility within the field

- Retaining the copyright to your article

Submit your next manuscript at $>$ springeropen.com 